\begin{tabular}{|c|c|c|}
\hline \multirow{3}{*}{$\begin{array}{r}\text { Case Reports in } \\
\text { Gastroenterology }\end{array}$} & \multirow{2}{*}{\multicolumn{2}{|c|}{ Case Rep Gastroenterol 2013;7:409-413 }} \\
\hline & & \\
\hline & $\begin{array}{l}\text { DOI: } 10.1159 / 000355345 \\
\text { Publisned onIIne: september 11, } 2013\end{array}$ & $\begin{array}{l}\text { ○ } 2013 \text { S. Karger AG, Basel } \\
\text { 1662-0631/13/0073-0409 } \$ 38.00 / 0 \\
\text { www.karger.com/crg }\end{array}$ \\
\hline & \multicolumn{2}{|c|}{$\begin{array}{l}\text { This is an Open Access article licensed under the terms of the Creative Common } \\
\text { Attribution-NonCommercial } 3.0 \text { Unported license (CC BY-NC) (www.karger.com/OA } \\
\text { license), applicable to the online version of the article only. Distribution permitted for non } \\
\text { commercial purposes only. }\end{array}$} \\
\hline
\end{tabular}

\title{
Toxic Megacolon and Acute Ischemia of the Colon due to Sigmoid Stenosis Related to Diverticulitis
}

\author{
$\begin{array}{llll}\text { P. Antonopoulos } & \text { M. Almyroudi } & \text { V. Kolonia } & \text { S. Kouris } \\ & \end{array}$ \\ N. Troumpoukis ${ }^{a} \quad$ N. Economou ${ }^{c}$
}

${ }^{a}$ Computed Tomography and Magnetic Resonance Imaging Department, ${ }^{b}$ Second Department of Internal Medicine and ' Department of Surgery, Sismanogleio General Hospital, Athens, Greece

\section{Key Words}

Diverticulitis complications · Colonic dilation · Ischemia · Toxic megacolon

\begin{abstract}
We present a rare case of toxic megacolon accompanied by necrosis of the colon due to chronic dilation caused by stenosis of the sigmoid colon as a complication of diverticulitis. The patient presented at the emergency department with diffuse abdominal pain, fever $\left(38.8^{\circ} \mathrm{C}\right)$ and tachycardia (120 beats/min). Physical examination revealed distension and tenderness on deep palpation on the left lower quadrant without peritoneal signs. Abdominal computed tomography showed located stenosis in the sigmoid colon and marked dilation of the descending (12 cm diameter) and transverse $(7.5 \mathrm{~cm}$ diameter) colon. A few hours later, the patient developed severe septic shock with electrolyte abnormalities. He had a history of two prior admissions to our hospital due to crises of acute diverticulitis. Based on Jalan's criteria the diagnosis was compatible with toxic megacolon. The patient's condition deteriorated suddenly and an emergency colectomy was performed. The operative findings revealed a necrotic colon. Histology examination confirmed the diagnosis of ischemia of the colon. To our knowledge this is the first published report in the literature which refers to a rare complication of diverticulitis, namely chronic stenosis which complicated to colonic ischemia and toxic megacolon.


Antonopoulos et al.: Toxic Megacolon and Acute Ischemia of the Colon due to Sigmoid Stenosis Related to Diverticulitis

\section{Introduction}

Diverticulosis is a very common disease in the population over the age of 70. It affects the sigmoid and descending colon in more than $90 \%$ of patients [1]. The true incidence of colonic diverticulosis is difficult to measure, mainly because most patients are asymptomatic. The incidence clearly increases with age, and $80 \%$ of patients who present with diverticulitis are over the age of 50 [2]. Stenosis is reported as a very rare complication and only $0.09 \%$ of patients with diverticulosis develop diverticulitis and subsequent stenosis [3]. Diverticulitis is the second most common cause of large bowel obstruction caused by severe spasm, an adjacent walled-off abscess and fibrous scarring. Colonic dilation (cecum $>9 \mathrm{~cm}$ or transverse colon $>6 \mathrm{~cm}$ ) can be seen in adult patients presenting with a variety of medical and surgical conditions of the abdomen [4].

Due to the fact that dilation of the colon may lead to colonic ischemia-necrosis or perforation, an early and accurate diagnosis of the cause of dilation is necessary in order to prevent complications and to treat the patient appropriately. Computed tomography (CT) evaluation of the abdomen is the examination of choice when mesenteric ischemia is suspected because of its ability to provide two-dimensional multiplanar and threedimensional display of the mesenteric vasculature [5]. However, communication between the clinician and the radiologist remains imperative to facilitate the effective management of complications of diverticulitis.

This report describes and discusses a case of sigmoid stenosis due to diverticulitis and chronic dilation of the colon which evolved in chronic ischemia and was complicated by toxic megacolon and ischemia-necrosis of the colon. To the best of our knowledge there are very few reports in the literature referring to toxic megacolon and ischemia-necrosis of the colon due to stenosis of the sigmoid colon as a result of diverticulitis.

\section{Case Presentation}

A 40-year-old man presented to the accident and emergency department with severe diffuse abdominal pain which had started $8 \mathrm{~h}$ earlier. He also reported abdominal bloating, diarrhea and nausea. In his past medical history he had two episodes of acute diverticulitis over the past 2 years. Ten years prior to this presentation he had been hospitalized for a ruptured diverticulum in the sigmoid colon. As he refused to have surgery he was treated conservatively at that time.

On physical examination his temperature was $38.8^{\circ} \mathrm{C}$ and his heart rate was 120 beats/min. Blood pressure and oxygen saturation (while breathing ambient air) were normal. He had abdominal distension and tenderness on deep palpation on the left lower quadrant without peritoneal signs. Rectal examination revealed no stool in the vault. Laboratory examination revealed: hemoglobin $15.9 \mathrm{~g} / \mathrm{dl}$, WBC 19.120 (NEUT 80.2\%), CRP $270.6 \mathrm{mg} / \mathrm{l}, \mathrm{CPK} 543 \mathrm{U} / \mathrm{l}, \mathrm{GLU} 125 \mathrm{mg} / \mathrm{dl}, \mathrm{LDH} 481 \mathrm{U} / \mathrm{l}$, fibrinogen $4.4 \mathrm{~g} / \mathrm{l}, \mathrm{Na} 141 \mathrm{mEq} / \mathrm{l}$, and $\mathrm{K} 5.2 \mathrm{mEq} / \mathrm{l}$.

An abdominal CT scan showed located stenosis of the sigmoid colon and marked dilation of the descending ( $12 \mathrm{~cm}$ diameter), transverse $(7.5 \mathrm{~cm}$ diameter $)$ and ascending $(12 \mathrm{~cm}$ diameter) colon and of the cecum (11 cm diameter) (fig. 1). It is to be noted that in one of his prior admissions due to a crisis of acute diverticulitis 2 years earlier, CT scan had showed a stenotic lesion in the sigmoid colon with mechanical obstruction and prestenotic dilation of the colon. Before the latest admission he had experienced mild periodic discomfort in the abdomen but had not sought medical treatment. 
Antonopoulos et al.: Toxic Megacolon and Acute Ischemia of the Colon due to Sigmoid Stenosis Related to Diverticulitis

Over a period of $8 \mathrm{~h}$ the patient deteriorated with signs of sepsis, multiorgan failure, severe dyspnea and metabolic acidosis. A CT scan was performed which ruled out pulmonary embolism. He was then intubated because of respiratory muscle fatigue. Laboratory tests changed to the following values: CRP $318 \mathrm{mg} / \mathrm{l}$, CPK $543 \mathrm{U} / \mathrm{l}$, fibrinogen $6 \mathrm{~g} / \mathrm{l}$, creatinine $2.2 \mathrm{mg} / \mathrm{dl}$, PT $28.20 \mathrm{~s}$, INR 2.56, D-dimer 2,223.2 $\mu \mathrm{g} / \mathrm{l}$, Na $133 \mathrm{mEq} / \mathrm{l}, \mathrm{K} 5.4$ $\mathrm{mmol} / \mathrm{l}$, and P $5.4 \mathrm{mg} \%$.

The above clinical and laboratory findings were compatible with toxic megacolon. A surgical assessment was performed and emergency laparotomy was decided. Surgery revealed extensive necrotic colon and total colectomy was implemented with protective loop ileostomy. After surgery the patient was transferred to the intensive care unit because of hemodynamic instability. He was extubated after $12 \mathrm{~h}$ and transferred to the ward where he stayed until his discharge 10 days later. Histological examination of the resected colon revealed resolving necrotic colon. The specimen was negative for malignancy. The loop ileostomy was reversed 3 months later. Today, 4 years later, the patient remains in good health.

\section{Discussion}

Diverticulitis is an uncommon disease in patients younger than 45 years [6, 7]. The most common complications of diverticulitis include abscess or phlegmon formation, fistula formation, stricture disease, bowel obstruction and peritonitis [8]. In recent years, CT scanning has been the initial radiologic examination and the method of choice for the diagnosis of acute diverticulitis $[9,10]$.

Recent reports in the literature refer to a new condition of chronic diverticulitis. This disease is a distinct pathologic entity characterized by the frequent development of chronic obstructive symptoms. It can often be diagnosed on the basis of its characteristic clinical and radiographic findings [11]. Chronic diverticulitis is supposed to be the cause of only $10 \%$ of large bowel obstructions [12]. Stenosis of the colon can occur as a result of chronic diverticulitis in the left-sided colon. The chronic inflammation can cause fibrosis-obstruction of the colonic lumen and change of bowel habit with increasing constipation and lower abdominal pain $[7,13]$.

In occasional cases, the differential diagnosis of sigmoid stenosis and diverticulitis from carcinoma is difficult [14]. The critical issue is to distinguish between a diverticular stricture and a stenosing neoplasm. Moreover, it is noted that there is an increased risk of left-sided colon cancer in patients with diverticular disease of the sigmoid colon [15]. Magnetic resonance imaging and CT provide information that may contribute to the differentiation between sigmoid cancer and diverticulitis [16].

Distension of the colon due to chronic stenosis can lead to continuous ischemia of all bowel wall layers and finally necrosis of the colon segment proximal to the obstruction. Ischemia due to dilation of the colon may be provoked when there is an increase in intraluminal pressure to more than $50 \mathrm{~mm} \mathrm{Hg}$ [17]. Acute colonic ischemia has a high mortality rate, depending on the cause of the event, the degree of ischemia and the extent of the ischemic bowel. In certain cases, bacterial overgrowth within the prestenotic segment may also contribute to the pathogenesis of intestinal necrosis [17].

Toxic megacolon is a complication of various inflammatory and ischemic diseases of the colon, but most often it is associated with inflammatory bowel disease. Ischemia and amebic colitis may also produce a toxic megacolon pattern [4]. The diagnosis of toxic megacolon according to Jalan's criteria includes the radiographic finding of dilation $(>6 \mathrm{~cm}$ in the 
Antonopoulos et al:: Toxic Megacolon and Acute Ischemia of the Colon due to Sigmoid Stenosis Related to Diverticulitis

transverse colon on radiologic examination) as well as three of the following four features: fever $>38.6^{\circ} \mathrm{C}$, tachycardia (heart rate $>120$ beats $/ \mathrm{min}$ ), $\mathrm{WBC}>10,500$ and anemia, plus at least one of the following: volume depletion, mental status changes, electrolyte abnormalities or hypotension. Our patient presented with fever $>38.6^{\circ} \mathrm{C}$, tachycardia $>120$ beats $/ \mathrm{min}$, leukocytosis (WBC $>10,500$ ), mental status changes, electrolyte abnormalities and signs of septic shock. Toxic megacolon complicating inflammatory or infective colitis carries a high morbidity and mortality, and surgical intervention is necessary in up to $80 \%$ of cases [18].

The policy of prophylactic surgery, the timing and the appropriateness of treatment of sigmoid diverticulitis remain a topic of controversy. While it remains primarily a surgically treated disease, medical treatments, such as mesalamine, and evolving endoscopic techniques allow the gastroenterologist to play an important role in the management of these patients [19]. Because of the fact that many authors believe that diverticulitis is a more virulent disease in younger patients, it has been argued that all patients younger than 50 years should undergo elective colon resection after an initial attack of diverticulitis [20]. However, we believe that elective surgery should be reserved for those who have had at least two episodes of severe diverticulitis [21].

Recurrent attacks of diverticulitis, which may be subclinical, can initiate progressive fibrosis and stricturing of the colonic wall in the absence of ongoing inflammation. A number of reports have described the relative safety and efficacy of such therapy for strictures of various etiologies, utilizing varied techniques such as bouginage, balloon, laser, electrocautery and a blunt dilating endoscope $[22,23]$. Moreover, self-expanding metal stents can effectively decompress high-grade, benign colonic obstruction, thereby allowing elective sigmoidectomy. Self-expanding metal stents can be used as a bridge to surgery in diverticular obstruction, but there seems to be a considerable risk of complications. If a selfexpanding metal stent is placed into a diverticular stricture, the planned bowel resection should be performed within a month [24].

\section{References}

1 Stollman NH, Raskin JB: Diverticular disease of the colon. J Clin Gastroenterol 1999;29:241-252.

-2 Ambrosetti P, Robert JH, Witzig JA, Mirescu D, Mathey P, Borst F, Rohner A: Acute left colonic diverticulitis: a prospective analysis of 226 consecutive cases. Surgery 1994;115:546-550.

3 Nishiyama N, Mori H, Kobara H, Rafiq K, Fujihara S, Kobayashi M, Masaki T: Difficulty in differentiating two cases of sigmoid stenosis by diverticulitis from cancer. World J Gastroenterol 2012;18:3623-3626.

4 Krajewski K, Siewert B, Eisenberg RL: Colonic dilation. AJR Am J Roentgenol 2009;193:W363-W372.

5 Levy AD: Mesenteric ischemia. Radiol Clin North Am 2007;45:593-599.

-6 Lahat A, Menachem Y, Avidan B, Yanai H, Sakhnini E, Bardan E, Bar-Meir S: Diverticulitis in the young patient - is it different? World J Gastroenterol 2006;12:2932-2935.

7 Andersen JC, Bundgaard L, Elbrønd H, Laurberg S, Walker LR, Støvring J; Danish Surgical Society: Danish national guidelines for treatment of diverticular disease. Dan Med J 2012;59:C4453.

8 Jacobs DO: Clinical practice. Diverticulitis. N Engl J Med 2007;357:2057-2066.

-9 Sarma D, Longo WE; NDSG: Diagnostic imaging for diverticulitis. J Clin Gastroenterol 2008;42:1139-1141.

10 Stefánsson T, Nyman R, Nilsson S, Ekbom A, Påhlman L: Diverticulitis of the sigmoid colon. A comparison of CT, colonic enema and laparoscopy. Acta Radiol 1997;38:313-319.

11 Sheiman L, Levine MS, Levin AA, Hogan J, Rubesin SE, Furth EE, Laufer I: Chronic diverticulitis: clinical, radiographic, and pathologic findings. AJR Am J Roentgenol 2008;191:522-528.

-12 Buckley O, Geoghegan T, O’Riordain DS, Lyburn ID, Torreggiani WC: Computed tomography in the imaging of colonic diverticulitis. Clin Radiol 2004;59:977-983.

13 Miyamoto R, Koizumi M, Terashima T, Abe R, Katsura K, Kato T, Ohtani H: Chronic diverticulitis of the large intestine characterized by stenosis symptoms in Japan: report of 6 cases. Clin J Gastroenterol 2012;5:47-52. Klarenbeek BR, Samuels M, van der Wal MA, van der Peet DL, Meijerink WJ, Cuesta MA: Indications for elective sigmoid resection in diverticular disease. Ann Surg 2010;251:670-674.

15 Stefánsson T, Ekbom A, Sparèn P, Påhlman L: Association between sigmoid diverticulitis and left-sided colon cancer: a nested, population-based, case control study. Scand J Gastroenterol 2004;39:743-747. 


\begin{tabular}{l|l}
\hline \multicolumn{2}{l}{ Case Rep Gastroenterol 2013;7:409-413 } \\
\hline DOI: 10.1159/000355345 & $\begin{array}{l}\text { C 2013 S. Karger AG, Basel } \\
\text { www.karger.com/crg }\end{array}$ \\
\hline
\end{tabular}

Antonopoulos et al:: Toxic Megacolon and Acute Ischemia of the Colon due to Sigmoid Stenosis Related to Diverticulitis

16 Öistämö E, Hjern F, Blomqvist L, Von Heijne A, Abraham-Nordling M: Cancer and diverticulitis of the sigmoid colon. Differentiation with computed tomography versus magnetic resonance imaging: preliminary experiences. Acta Radiol 2013;54:237-241.

17 Wiesner W, Khurana B, Ji H, Ros PR: CT of acute bowel ischemia. Radiology 2003;226:635-650.

18 Panos MZ, Wood MJ, Asquith P: Toxic megacolon: the knee-elbow position relieves bowel distension. Gut 1993;34:1726-1727.

19 Weizman AV, Nguyen GC: Diverticular disease: epidemiology and management. Can J Gastroenterol 2011;25:385-389.

20 Wong WD, Wexner SD, Lowry A, Vernava A 3rd, Burnstein M, Denstman F, Fazio V, Kerner B, Moore R, Oliver G, Peters W, Ross T, Senatore P, Simmang C: Practice parameters for the treatment of sigmoid diverticulitis - supporting documentation. The Standards Task Force. The American Society of Colon and Rectal Surgeons. Dis Colon Rectum 2000;43:290-297.

21 Bordeianou L, Hodin R: Controversies in the surgical management of sigmoid diverticulitis. J Gastrointest Surg 2007;11:542-548.

22 Kozarek RA: Hydrostatic balloon dilation of gastrointestinal stenoses: a national survey. Gastrointest Endosc 1986;32:15-19.

23 Blomberg B, Rolny P, Jarnerot G: Endoscopic treatment of anastomotic strictures in Crohn's disease. Endoscopy 1991;23:195-198.

24 Keränen I, Lepistö A, Udd M, Halttunen J, Kylänpää L: Outcome of patients after endoluminal stent placement for benign colorectal obstruction. Scand J Gastroenterol 2010;45:725-731.

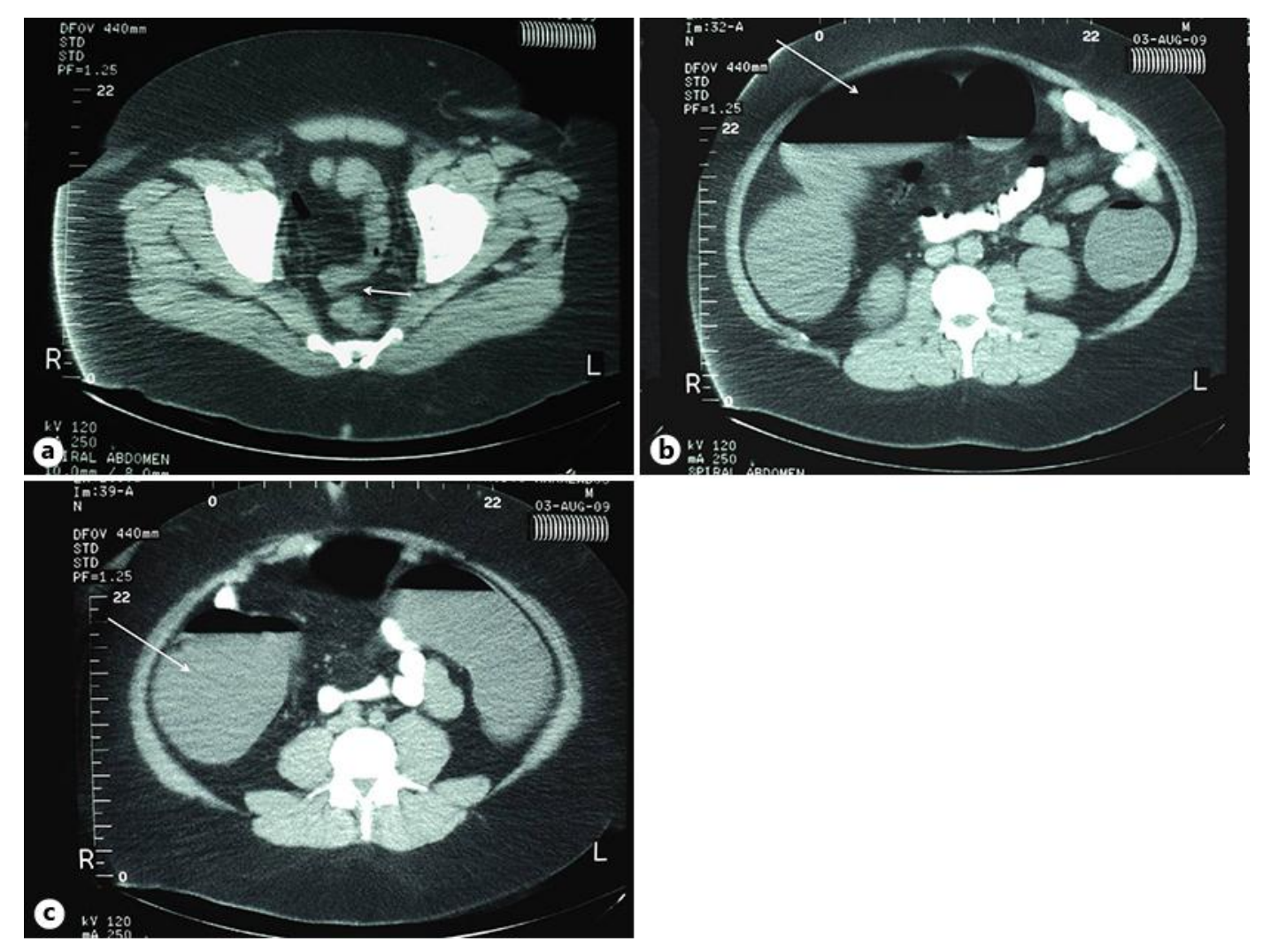

Fig. 1. Abdominal CT showed a stenotic lesion of the sigmoid colon and extensive prestenotic dilation. a Stenosis of the sigmoid colon, length $12 \mathrm{~cm}$ (arrow). b Dilation of the transverse colon (arrow). c Dilation of the ascending colon until the ileocecal valve (arrow). 